\title{
Anesthetic Consideration on Neonatal Patient with Esophageal Atresia
}

\author{
Reza Sudjud, Tatang Bisri, Cindy Elfira Boom \\ Department of Anesthesiology and Intensive Care, Faculty of Medicine, Padjadjaran University, Bandung, West Java, Indonesia \\ Email: sudjudreza@gmail.com
}

How to cite this paper: Sudjud, R., Bisri, T. and Boom, C.E. (2016) Anesthetic Consideration on Neonatal Patient with Esophageal Atresia. Open Journal of Anesthesiolo$g y, 6,128-136$.

http://dx.doi.org/10.4236/ojanes.2016.69022

Received: August 1, 2016

Accepted: September 25, 2016

Published: September 28, 2016

Copyright $\odot 2016$ by authors and Scientific Research Publishing Inc. This work is licensed under the Creative Commons Attribution International License (CC BY 4.0).

http://creativecommons.org/licenses/by/4.0/ c) (i) Open Access

\begin{abstract}
Esophageal atresia is a disorder of the esophageal continuity with or without a connection with the trachea or the under-development esophagus. Most babies who suffer from esophageal atresia also have tracheoesophageal fistula (an abnormal connection between the esophagus and the trachea/windpipe). The possibility of these two conditions is accompanied by other anomalies such as congenital heart disease and anorectal malformations. Esophageal atresia can also be interpreted as malformations caused by the failure of the esophagus to develop a continual passage that may or may not establish a connection to the trachea (tracheoesophageal fistula) or it can be said that the esophageal atresia is the failure of the esophagus to form a channel from the pharynx to the stomach during embryonic development. Another understanding of esophageal atresia is an interruption in the growth of a segment of the esophagus and remains as thin sections without continual channels. Tracheal esophageal fistula is an abnormal connection between the trachea and esophagus. Miscellaneous types of esophageal atresia include: Type A. The incidence of Type A esophageal atresia was about 5\% - 8\%. Type A esophageal atresia occurs at each end of the esophageal sac, and is apart without fistula to the trachea. Type B incident is rare. Type $B$ esophageal atresia occurs at each end of the esophagus, and there is fistula from the trachea to the upper segment of esophagus. Incidence of Type C esophageal atresia occurs about $80 \%$ - 95\%. Type C esophageal atresia occurs at the proximal esophageal segment and ends at a dead-end sac, and distal segments are connected to the trachea or primary bronchus. Type $\mathrm{D}$ esophageal atresia is rare. In this type, upper and lower segment of the esophagus is connected to the trachea. Type $\mathrm{E}$ esophageal atresia is rare when compared with Types A and C esophageal atresia. In this type the esophagus and trachea are normal but they are connected with fistula.
\end{abstract}

\section{Keywords}

Anesthesia, Neonatal, Esophageal, Atresia 


\section{History Taking}

An 8-day-old baby girl consulted from the pediatric surgeon with complaints of obstruct ion of gastrointestinal tract and had no anus. Patients were born from P1A0 34-week pregnant mothers under Caesarean section with fetal distress as indication. After birth, at the age of 20 hours, patients underwent gastrostomy and colostomy surgery in another hospitals, then had admitted to the NICU for 5 days and then referred to Hasan Sadikin Hospital at the request of the family.

During previous hospitalization, patients had suffered shortness of breath with improvement after mucous suction periodically. Shortness of breath had been observed since birth and has undergone improvement.

\section{Physical Examination}

From the physical examination found the general condition was compost mentis, actively crying, HR $148 \times / \mathrm{mnt}$, RR $40 \times / \mathrm{mnt}$, Temperature 36.8 , and $\mathrm{O}_{2}$ Sat. $96 \%-97 \%$ with the head box, Body weight was 2500 grams. On Lung examination rhonchi and wheezing were not found and other physical examination within normal limits. Gastrostomy tube was effective and colostomy was also vital and effective

\section{Laboratory Examination}

Laboratory results from the pre-operative can be seen below:

August 18, 2013
PT/INR/APTT
10.7/0.84/29.0
$\mathrm{Hb} / \mathrm{Ht} / \mathrm{L} / \mathrm{Tr}$
14.1/39/10,600/299,000
SGOT/SGPT
16/8
Total bilirubin/direct bilirubin
$11.97 / 0.96$
Ur/Cr
$36 / 0.55$
Random blood glucose
96
Na/K
$133 / 3.7$
Free Ca ion
5.71

Chest X-ray: no bronchopneumonia and cardiomegaly

Consulted to pediatric cardiologist (08/16/2013): no cardiac abnormalities was found Consulted to pediatrician (08/16/2013): no pulmonary abnormalities was found

Diagnosis: esophageal atresia with distal type treacheoesophageal fistula and anorectal malformation post gastrostomy and post colostomy. 


\section{Preoperative Period}

Finally, complete content and organizational editing before formatting. Please take note of the following items when proofreading spelling and grammar: Grade II ASA.

Suggestion:

Fasting 6 hours pre-op-administer breath milk 4 hour pre-op, and administer clear water 2-hour pre-op.

Blood for transfusion is prepared.

\section{Operative Period}

During operation $(20 / 08 / 2013)$

Pk. 09:30

Patient was brought into the operating room, ECG and $\mathrm{O}_{2}$ saturation are installed. The patient's general state is active, HR $158 \times / \mathrm{min}, \mathrm{RR} 40 \times / \mathrm{mnt}, \mathrm{O}_{2}$ Sat $97 \%$ by binasalcanul $1 \mathrm{ltr} / \mathrm{min}$.

Induction using inhalational anesthesia with sevoflurane $2 \mathrm{MAC}$, patient allowed to breath spontaneously and then intubated with No. 3.0 ETT then placed between fistula and carina, by investigating gastrostomi tube which is soaked in the water, no air bubbles and the sound of the left and right lung are same. After ETT fixed, precordial stethoscope was strapped on patient's chest, then administered fentanyl $2 \mathrm{mcg} / \mathrm{kg}$ and atracurium $0.5 \mathrm{mg} / \mathrm{kg}$, the patient is placed in the left lateral decubitus. The operation lasted for 5 hours.

Intra-op finding:

Distance between proximal and distal stump was $1 \mathrm{~cm}$, proximal stump size was 1 $\mathrm{cm}$ as high as thoracal III, distal stump on the left side of vertebral body, size $0.5 \mathrm{~cm}$, as high as right aortic arch.

After the completion of the operation, the patient had spontaneous breathing, then extubated. Patients already actively crying, HR $130 \times / \mathrm{min}, \mathrm{RR} 40 \times / \mathrm{mnt}, \mathrm{O}_{2}$ sat $97 \%$ with nasal cannule $1 \mathrm{lpm}$. Our staff directly transfers the patient to NICU, hospitalized for 17 days and then the patient is allowed to go home.

\section{Discussion}

\subsection{Definition}

Esophageal Atresia is, a member group of congenital anomalies, disorder of esophageal continuities with or without a fistula with the trachea [1].

\subsection{Epidemiology}

Esophageal atresia was first proposed by an expert pediatric, Hirscprung, from Copenhagen in the 17th century to be exact in 1862 with approximately 14 cases of esophageal atresia, this disorder has been suspected as a malformation of the gastrointestinal tract [1]. In 1941 a surgeon name Cameron Haight of Michigan have successfully performed surgery on esophageal atresia and since then, it was included in the group of congenital 
abnormalities that can be fixed [2].

In North America the incidence of esophageal atresia ranges from 1:3000 - 4500 of live births, the rate is decreasing with an unknown cause [3]. Internationally the incidence is highest in Finland is about 1 in 2500 live births [4]. Esophageal atresia is 2 - 3 times more common in twin fetuses [5].

\subsection{Etiology}

Until now unknown what teratogen substances that can cause abnormalities of esophageal atresia, recurrent case reported only about $2 \%$ if one of the twin sibling is affected [6]. Esophageal atresia was associated with trisomy syndrome 21.13 and 18 with suspected genetic cause. But this time, the theory about the occurrence of esophageal atresia according to most experts no longer associated with a genetic disorder [7].

Debate on embryiopathologic process continues, and little is known [8].

\subsection{Classification}

The original classification by Vogt in 1912 is still in use today. Gross in 1953 modifying the classification, while Kluth 1976 published "Atlas Esophageal Atresia" which consists of 10 main types, with each subtype that is based on the original classification of Vogt. It looks easier to describe than to label anatomical abnormalities that are difficult to recognize (Figure 1) [9].

1) Esophageal atresia with distal fistula tracheoesophageal (86\% Vogt III, Gross C)

The most frequent manifestation in the proximal esophagus is dilation and thickening of the muscle which ended on thoracal III/IV vertebra. The distal esophagus (fistula), which is thinner and narrower, entered the posterior tracheal wall height or $1-2$ $\mathrm{cm}$ above carina. The distance between the proximal esophageal fistula and distal tracheoesophageal is variable.

2) Isolated esophageal atresia without fistula (7\%, Vogt II, Gross A)

The distal and proximal esophagus are actually ended up without a relationship with the proximal esophageal segment, dilation and wall thickening and usually end up as high as the posterior mediastinum around vetebra thoracic II. Distal esophagus end at different distances above diaphragm.

3) Tracheal esophageal fistula without atresia (4\%, Groos E)

There is a communication between the esophagus with trachea. Fistula tract like this can be very thin/narrow with a diameter of $3-5 \mathrm{~mm}$ and are generally located at the lowest cervical area. Usually single but maybe found two or even three fistulas.

4) Esophageal atresia with proximal esophageal tracheal fistula (2\%, Vogt III \& Gross B).

This type is rare but should be distinguished from isolated malformation. Fistula is not at the distal end of the esophagus but located $1-2 \mathrm{~cm}$ above the upper tip of the front wall of the esophagus.

5) Esophageal atresia with distal and proximal tracheal esophageal fistula

In most infants, this disorder is often missed and manage as atresia of the proximal 


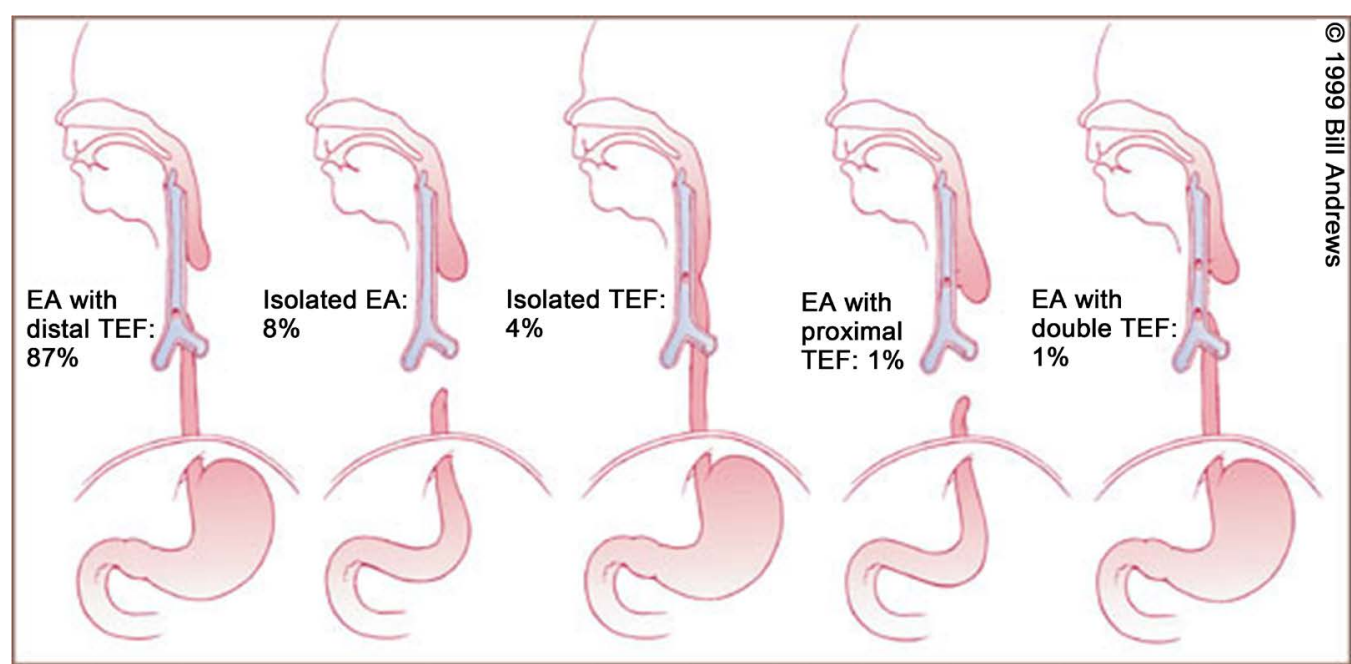

Dwayne C. Clark, Esophageal Atresia and Tracheoesophageal Fistula. Journals American Family Physician ${ }^{\circledR}$ Vol.59/ No. 4 (February 15, 1999).

Figure 1. Type of esophageal atresia.

and distal fistula. As a result, repeated respiratory tract infections often occured, examination can be carried out and showed a fistula can be fixed and overall condition will be improved.

\subsection{Pathology}

Esophageal atresia is characterized by the incomplete esophageal formation. It is often associated with a fistula between the trachea and esophagus. Many anatomical variations of esophageal atresia with or without tracheal esophageal fistula have been described (Table 1) [4].

This table provides a summary of the variations of the incidence on various surgical center in the world. The most frequent variants of these anomalies is with fistula between the trachea and the distal esophagus, which is estimated to occur $89 \%$ at the time. Fistula often occurs close to the carina [11].

Proximal esophageal pouch often hypertrophic and dilated due to attempted by baby swallows amniotic fluid, the muscles of the esophagus can suppress the trachea, and emphasis it contributes to the occurrence tracheomalacia [12].

Second deformities (8\%) that is often found is tracheaesophageal atresia without fistula, a condition associated with impaired development of distal esophagus so that the surgery will be more difficult.

Third Abnormalities (4\%) is the presence of H-type fistula which is tracheaesophagusfistula without esophageal atresia. This condition is difficult to diagnose clinically if the fistula long enough and oblique, the symptoms are more minimal and could not be found quickly [13].

\subsection{Clinical Manifestation and Diagnosis}

Diagnosis of esophageal atresia/tracheaesofagus fistula can be made before the baby is 
Table 1. Summary of six studies of the frequency of various types of esophageal atresia, tracheoesophageal fistula, or both.

\begin{tabular}{ccccccc}
\hline Study (dates) & $\begin{array}{c}\text { Number of } \\
\text { study subjects }\end{array}$ & $\begin{array}{c}\text { Type A } \\
\text { number }\end{array}$ & $\begin{array}{c}\text { Type B } \\
\text { number }\end{array}$ & $\begin{array}{c}\text { Type C } \\
\text { number }\end{array}$ & $\begin{array}{c}\text { Type D } \\
\text { number }\end{array}$ & $\begin{array}{c}\text { Type E } \\
\text { number }\end{array}$ \\
\hline German, et al. [9] (1964-1974) & 102 & 6 & 2 & 83 & 9 & 2 \\
Sillen, et al. [10] (1967-1984) & 110 & 7 & 1 & 100 & 1 & 1 \\
Holder, et al. [11] (1973-1986) & 100 & 2 & 1 & 85 & 6 & 6 \\
Poenaru, et al. [12] (1969-1989) & 95 & 8 & 0 & 80 & 1 & 6 \\
Engum, et al. [3] (1971-1993) & 227 & 29 & 2 & 178 & 5 & 13 \\
Spitz, et al. [1] (1988-1994) & 410 & 27 & 4 & 353 & 9 & 17 \\
Total & $\mathbf{1 0 4 4}$ & $\mathbf{7 9}$ (8\%) & $\mathbf{1 0}$ (1\%) & $\mathbf{8 7 9}$ (84\%) & $\mathbf{3 1}$ (3\%) & $\mathbf{4 5}$ (4\%) \\
\hline
\end{tabular}

Type $\mathrm{A}=$ pure esophageal atresia; Type $\mathrm{B}=$ esophageal atresia with proximal tracheoesophageal fistula; Type $\mathrm{C}=$ esophageal atresia with distal tracheoesophageal fistula; Type $\mathrm{D}=$ esophageal atresia with proximal and distal tracheoesophageal fistula; Type $\mathrm{E}=\mathrm{H}$-type tracheoesophageal fistula without esophageal atresia.

Dwayne C. Clark, Esophageal Atresia and Tracheoesophageal Fistula. Journals American Family Physcian ${ }^{\circledR}$ Vol.59/ No. 4 (February 15, 1999).

born. One of the early signs of esophageal atresia is known from prenatal ultrasound examination is polyhydramnios, where there are excessive amniotic fluid volume [5].

This sign is not a definitive diagnosis, but if found, one should consider the possibility of esophageal atresia [8].

Amniotic fluid normally undergoes a circulation process by means swallowed, excreted through urine. In esophageal atresia/fistula esophageal the swallowed amniotic fluid is expelled because of the accumulated fluid in the pouch of the esophagus thus increasing the amount of amniotic fluid [11].

Diagnosis of esophageal atresia is suspected in the prenatal period in which there is little stomach bubbles (bubble stomach) or not found on ultrasound after 18 weeks pregnancy. Overall sensitivity of ultrasound is about $42 \%$. Polihidraminon itself is a weak indication of esophageal atresia (incidence of 1\%). Available methods to increase the number of prenatal diagnostics including ultrasound examination of the fetal neck to describe the "dead end" on the bag and assess fetal's process of ingestion under MRI [6].

Newborns with maternal polyhydramnios should show a nasogastric tube is able to pass soon after birth to rule out esophageal atresia. Infants with esophageal atresia unable to swallow saliva and and require repeated suction [7]. In this phase the course before eating for the first time, bore rigid catheter must be passed through the mouth to the esophagus. In esophageal atresia, the rigid catheter cannot pass beyond $9-10 \mathrm{~cm}$ of alveolar bottom and under chest and abdominal X-ray, it shows the catheter tip is stuck at superior mediastinum (T2-4), while the gas in the stomach and intestines showed distal trakeaesofagus fistula. The absence of gastro intestinal gas suggests an isolated esophageal atresia.

Newborns who suspected suffering from atresia esophageal/fistula tracheoesophageal should perform X-ray examination. The picture is dilation of the esophagus bags, be- 
cause of the accumulation of prenatal amniotic fluid [8].

During fetal development, the enlargement of the esophagus causing pressure and constriction to the trachea. This condition can lead to fistula. The presence of air in the stomach to make sure the existence of fistula while the gas in the large intestine to get rid of their duodenal atresia [10].

\subsection{Other Congenital Abnormalities Associated with Esophageal Atresia}

More than $50 \%$ of infants with esophageal atresia have one or more additional disorders, such as: [3]

1) Cardiovascular: $29 \%$

2) Vetebral/skeletal: $10 \%$

3) Anorectal disorders: $14 \%$

4) Respiratory: $6 \%$

5) Genitourinary: $14 \%$

6) Genetic: $4 \%$

7) Gastrointestinal: $13 \%$

8) Others: $11 \%$

There is a relationship between the incidence of the abnormalities and the type of esophageal atresia, in pure atresia (65\%) and the incidence of the type- $\mathrm{H}$ fistula (10\%) VATER was first described by Quan and Smith in 1973 consisted of a combination of abnormalities including (Vetebra, anorectal, tracheaesofageal and renal). The group then modified into VACTERL therefore included heart defects and limb.

Congenital anomalies are found nearly half of the infants with esophageal atresia. Most babies have more than one congenital abnormalities. Cardiac anomalies occur at nearly $1 / 4$ the number of infants with esophageal atresia. VSD, PDA and Tetralogy of Fallot are the most frequently reported. More complex heart defects often associated with other multiple anatomic defects and is associated with poor outcome [4].

Gastrointestinal anomalies that often happens is duodenal atresia, ileal atresia, hypertrophy pyloric stenosis, omphalocele, Meckel's diverticulum. Abnormalities of the urinary tract malformations such as ureters abnormalities, Hypospadia and kidney agenesis also can occur [6].

Approximately $10 \%$ of infants with esophageal atresia suffer Vater or VACTERL (Vetebral defects, Anorectal malformations, heart defects, tracheoesophageal fistula, Renal anomalies, limb deformity) has been used to describe multiple anomalies in this state. Ten percent of infants with esophageal atresia suffer Vater syndrome. Esophageal atresia alone (isolated) is associated with a high incidence of other malformations compare to esophageal atresia with tracheal esophageal fistula [7].

\section{Post Operative Care}

Immediately after surgery the patient was admitted at the NICU with care as follows [3]: 
1) Monitor respiration, body temperature, cardiac and renal function.

2) Oxygen must be given and respiratory ventilator can be given if needed analgesics are given if needed.

3) Blood tests and urine tests are done to evaluate the overall state of the fetus.

4) Esophageal scanning is done to evaluate esophageal function.

5) Feeding is provided through a tube that is inserted directly to the stomach (gastrostomy) or simply by administering intravenous parentral nutrition until the baby can swallow food.

6) The discharge is suctioned through the throat with a nasogastric tube.

Hospitalizations approximately 2 weeks or more, depending on the occurrence of the complications that could arise under these conditions. Esophagography examination carried out in the second, sixth, one year after surgery to monitor the function of the esophagus [6].

\section{Complication}

Complications that can arise after esophageal atresia and esophageal atresia fistula have been repaired is as follows [5]:

1) Esophageal dysmotility. Dysmotility occur because of esophageal wall muscle weakness. Various levels of dysmotility may occur after this operation. This complication is seen when the baby has started eating and drinking.

2) Gastroesophageal reflux. Approximately $50 \%$ of infants who undergo this surgery will experience gastroesophageal reflux during childhood or adulthood, where stomach acid up or reflux into the esophagus. This condition can be corrected with medication or surgery.

3) Tracheaesophageal recurrent fistula. Surgery is the treatment for this condition.

4) Dysphagia, or difficulty swallowing. Dysphagia is a retention of food in the repaired esophagus. This situation can be overcome by swallowing water for ingestion of food.

5) Difficulty in breathing and choking. These complications associated with ingestion of food, food retention and aspiration of food into the trachea.

6) Chronic cough. Cough is a common symptom after esophageal atresia repair surgery, this is due to the weakness of the trachea.

7) Increased respiratory tract infections. Prevention of this condition is to avoid contact with people suffering from flu, and increase immune function by taking vitamins and supplements.

\section{Conclusions}

1) Esophageal atresia is a congenital disorder of the digestive tract that can be detected from antenatal period (prenatal).

2) Comprehensive treatment can improve the life expectancy of patients with esophageal atresia.

3) Prognosis of esophageal atresia depends on many other congenital abnormalities 
and complications suffered by the baby.

4) Management of proper anesthesia can make a better prognosis.

\section{References}

[1] Spitz, L. (2007) Oesophageal Atresia. Orphanet Journal of Rare Diseases, 2, 24. http://dx.doi.org/10.1186/1750-1172-2-24

[2] Sadler, T. (2000) Sistem Pencernaan. Dalam: Embriologi Kedokteran Langman. EGC, Jakarta, 243-248.

[3] Dunkley, M.E., Zalewska, K.M., Shi, E. and Stalewski, H. (2014) Management of Esophageal Atresia and Tracheoesophageal Fistula in North Queensland. International Surgery, 99, 276-279. http://dx.doi.org/10.9738/INTSURG-D-13-00253.1

[4] Clark, D.C. (1999) Esophageal Atresia and Tracheoesophageal Fistula. Journals American Family Physician, 59, 919-920.

[5] Kabesh. A. (2004) Esophageal Atresia and Tracheoesophageal Fistulae. ASJOG, I, 81-83.

[6] Allan, W., et al. (2000) Esophageal Atresia Repair. Pediatric Gastrointestinal Disease: Pathophysiology, Diagnosis, Management. 3rd Edition, B.C. Decker, Boston.

[7] Carta, M., et al. (2004) Long Gap Esophageal Atresia and Associated Anomalies. Italian Journal of Pediatrics, 30, 184-188.

[8] Ezzeldin, A., et al. (2003) Five Year Experience in Prenatal Ultrasound Diagnosis of Esophageal Atresia in Saudi Arabia. Annals of Saudi Medicine, 23, 132-134.

[9] Bryan, D. (1999) Charge Syndrome; Esophageal Atresia and Tracheoesaphageal Fistula. Charge Syndrome Foundation, Inc., New York, Section III-11.

[10] Werner, H. (2007) Esophageal Atresia. Clínica de Diagnóstico por Imagem, CDPI, Rio de Janeiro, Brazil. https://sonoworld.com/fetus/page.aspx?id=2217

[11] Marquette, G.P. (2004) First-Trimester Imaging of Combined Esophageal and Duodenal Atresia without a Tracheoesophageal Fistula. Journal of Ultrasound in Medicine, 23, 1232.

[12] Krishna, A. (1994) Factors Influencing Survival in Esophageal Atresia. Indian Pediatrics, 31, 80-83.

[13] Balakumar, K. (2004) Antenatal Ultrasound Screening for Anomalies among SingletonsResults of a Prospective Study. Calicut Medical Journal, 2, e9. 
Submit or recommend next manuscript to SCIRP and we will provide best service for you:

Accepting pre-submission inquiries through Email, Facebook, LinkedIn, Twitter, etc.

A wide selection of journals (inclusive of 9 subjects, more than 200 journals)

Providing 24-hour high-quality service

User-friendly online submission system

Fair and swift peer-review system

Efficient typesetting and proofreading procedure

Display of the result of downloads and visits, as well as the number of cited articles

Maximum dissemination of your research work

Submit your manuscript at: http://papersubmission.scirp.org/

Or contact ojanes@scirp.org 